\title{
BALL-ON-THREE-BALLS BIAXIAL FLEXURAL STRENGTH OF BONDED AND UNBONDED CAD/CAM MATERIALS
}

\author{
${ }^{\#}$ NOURAH SHONO, AHMED ELHEJAZI, AHMED MAAWADH, HEND AL NAHEDH \\ Department of Restorative Dentistry, College of Dentistry, King Saud University, Riyadh, Saudi Arabia \\ "E-mail: nshono@ksu.edu.sa
}

Submitted December 7, 2021; accepted January 11, 2022

\begin{abstract}
Keywords: Monolithic CAD/CAM ceramics, Physical properties, Fractographic analysis
This study aims to compare the biaxial flexural strength of four bonded and unbonded monolithic CAD/CAM restorative materials. Twenty disk-shaped specimens (10 $\mathrm{mm}$ in diameter and $2 \mathrm{~mm}$ in thickness) were fabricated from four CAD/CAM materials $(N=80)$ : IPS e.max CAD, VITA Suprinity, VITA Enamic, and DD cubeX'. The bonded and unbonded disks were subjected to biaxial flexural stress using a universal testing machine, followed by fractographic and scanning electron microscopic analysis of the fractured samples. In the unbonded group, a significant difference in the biaxial flexural strength was observed $(P<.0001): D D$ cubeX2 $(566.3 \mathrm{MPa})>\mathrm{IPS}$ e.max CAD $(410.5 \mathrm{MPa})>$ VITA Suprinity $(330.7 \mathrm{MPa})>$ VITA Enamic (247.3 MPa). In the bonded group, a statistically significant difference was noted: DD cubeX ${ }^{2}(676.5 \mathrm{MPa})$, VITA Enamic (619.3 MPa), IPS e.max CAD (605 MPa), and VITA Suprinity (544.2 MPa) $(P=0.009)$. When cemented, all the CAD/CAM materials showed an increase in the biaxial flexural strength. The bonded VITA Enamic exhibited values comparable to DD cubeX2 and significantly higher than IPS e.max CAD and VITA Suprinity.
\end{abstract}

\section{INTRODUCTION}

Ceramic materials from pressable to chairside Computer Aided Design and Manufacturing (CAD/CAM) blocks have undergone significant developments over the years. Their aesthetic and mechanical properties have made them the primary choice of dentists for restoring severely decayed teeth [1]. Currently, CAD/CAM materials are frequently used for the construction of indirect restorations. Over the last decade, monolithic anatomic contour restorations have been successfully used for the fabrication of indirect restorations [2,3]. The success is attributed to the improved mechanical properties and favourable translucency due to a more homogenous microstructure and simplified processing techniques, all of which result in reduced residual stresses within the final restoration [4-9].

Many CAD/CAM systems are available for clinicians to choose from, with each manufacturer claiming superior mechanical or optical properties, or both. One known system used is IPS e.max CAD (Ivoclar Vivadent); it is known to be made of a crystallised lithium disilicate glass-ceramic with an average flexural strength of $530 \mathrm{MPa}$ [10]. VITA Suprinity (VITA Zahnfabrik) is another CAD/CAM material available for the fabrication of monolithic restorations. Its strength is attributed to its composition of zirconia-reinforced lithium silicate glassceramic, which, according to the manufacturer, gives it a flexural strength of $420 \mathrm{MPa}$ [11]. Zirconia ceramics have undergone many advancements through the years, including those developed for monolithic restorations.
An example of which is DD cubeX ${ }^{2}$ (Dental Direkt), a third-generation 5 mol. \% yttria-stabilised tetragonal zirconia polycrystal ceramic developed to provide restorations with high aesthetics and strength. According to the manufacturer, the final restoration would yield a flexural strength of $720 \mathrm{MPa}$ [12].

CAD/CAM materials, other than ceramics, have been introduced to overcome some of the shortcomings of ceramics, particularly their brittleness. One example is VITA Enamic (VITA Zahnfabrik), a polymer-infiltrated ceramic network (PICN) composed of a glass-ceramic sintered network ( 75 vol. \%) with a urethane dimethacrylate/triethylene glycol dimethacrylate matrix. It has shown favourable optical and mechanical properties compared with glass-ceramics, with its flexural strength ranging from 130 to $140 \mathrm{MPa}$ [13-17].

The flexural strength, modulus of elasticity, and toughness of ceramics are some of the parameters that have been widely tested through the years $[9,15,18,19]$. The flexural strength of a material can be measured using uniaxial or biaxial flexural tests [20]. Biaxial flexural testing is a popular method used to measure the strength of dental ceramics [21-23]. The ball-on-3-balls (B3B), piston-on-3-balls, ball-on-ring, and ring-on-ring tests have all been found to be effective in testing the biaxial strength of dental ceramics [20]. However, the B3B test was specifically developed to overcome some disadvantages of conventional biaxial flexural tests, allowing for the slight warping of the sample surface without negatively affecting the mathematical calculations [21]. It is common practice for studies conducting 
flexural strength testing of CAD/CAM materials to prepare these materials into crowns, onlays, veneers, or disk-shaped specimens and then subject them to flexural stresses after cementing them to dentin analogues or natural teeth, although other studies forego cementation $[4,6,9,24-29]$. Sen and Us investigated the biaxial flexural strength of unbonded monolithic CAD/CAM restorative materials and found that VITA Suprinity exhibited the highest biaxial flexural strength, followed by IPS e.max CAD and VITA Enamic [9]. However, in a more recent study, Nishioka et al. observed that IPS e.max CAD showed the highest biaxial flexural strength compared with VITA Suprinity and VITA Enamic [26]. Comparative studies of the biaxial flexural strength of high translucent monolithic zirconia and that of IPS e.max CAD have also reported contrasting results, where the latter system would demonstrate higher biaxial flexural strength values in one study, but lower ones in another $[25,26]$. This inconsistency was also observed in studies examining the biaxial flexural strength of bonded monolithic CAD/CAM restorative materials [4,6,27,28]. On the other hand, consistent results were obtained by comparative studies of the biaxial flexural strength of IPS e.max CAD and that of VITA Enamic, with the latter system exhibiting lower strength than the former system whether it was bonded to dentin analogues or left unbonded [4,9,24,26,29]. More studies on monolithic $\mathrm{CAD} / \mathrm{CAM}$ restorative materials are clearly needed. A better understanding of the mechanical properties of such materials is critical, to enable better predictions of how the materials will clinically behave and also facilitate further improvements. Hence, the objective of this study was to investigate and compare the biaxial flexural strength (using the B3B test) of four bonded and unbonded monolithic CAD/CAM materials (IPS e.max
CAD, VITA Suprinity, VITA Enamic, and DD cubeX ${ }^{2}$ ) with a subsequent fractographic and scanning electron microscopic (SEM) analysis of the fractured samples. The following null hypotheses were tested: (1) there would be no significant difference in the biaxial flexural strength between the unbonded monolithic CAD/CAM materials; (2) there would be no significant difference in the biaxial flexural strength between the bonded monolithic CAD/CAM materials; and (3) there would be no significant difference in the biaxial flexural strength between the unbonded and bonded monolithic CAD/ CAM materials.

\section{MATERIALS AND METHODS}

Sample preparation

IPS e.max CAD, VITA Suprinity, VITA Enamic, and DD cubeX ${ }^{2}$ were used in this study. Details of these CAD/CAM materials are summarised in Table 1. The requisite subsample size of 20 disks from each material was determined with a $P$-value of 0.05 and a confidence interval of $95 \%$. In total, 80 disk-shaped specimens measuring $10 \mathrm{~mm}$ in diameter and $2 \mathrm{~mm}$ in thickness were fabricated. The specimens were designed (Sirona inEOS Blue; Dentsply), and then milled using a milling machine (Sirona inLab MC XL; Dentsply). The crystallisation of the IPS e.max CAD disks was performed using Programat P500 (Ivoclar Vivadent) following the manufacturer's instructions with a stand by temperature of $403{ }^{\circ} \mathrm{C}$; a closing time of 6 min; a heating rate of $90{ }^{\circ} \mathrm{C} \cdot \mathrm{min}^{-1}$; a firing temperature of $840{ }^{\circ} \mathrm{C}$ for $7 \mathrm{~min}$. Using the same abovementioned furnace, the VITA Suprinity disks were crystallised at $840{ }^{\circ} \mathrm{C}$ for $8 \mathrm{~min}$, and DD cube $\mathrm{X}^{2}$ disks were sintered at $1150{ }^{\circ} \mathrm{C}$

Table 1. Details of the study materials.

\begin{tabular}{|c|c|c|}
\hline Material & Company & Composition \\
\hline IPS e.max CAD & Ivoclar Vivadent & Lithium disilicate glass-ceramic \\
\hline VITA Suprinity & VITA Zahnfabrik & $\begin{array}{l}\text { Zirconia-reinforced lithium silicate glass-ceramic: } \mathrm{ZrO}_{2} \text { (zirconia), } \\
\mathrm{SiO}_{2} \text { (silicon dioxide), and } \mathrm{Li}_{2} \mathrm{O} \text { (lithium oxide) }\end{array}$ \\
\hline VITA Enamic & VITA Zahnfabrik & $\begin{array}{l}\text { Polymer-infiltrated (TEGDMA and UDMA) glass-ceramic } \\
\left(\mathrm{SiO}_{2}, \mathrm{Al}_{2} \mathrm{O}_{3}, \mathrm{Na}_{2} \mathrm{O}, \mathrm{K}_{2} \mathrm{O}, \mathrm{CaO} \text {, and } \mathrm{TiO}_{2}\right)\end{array}$ \\
\hline$\overline{\mathrm{DD} \text { cube } \mathrm{X}^{2}}$ & Dental Direkt & Highly translucent zirconia: $\mathrm{ZrO}_{2}+\mathrm{HfO}_{2}$ and $\mathrm{Y}_{2} \mathrm{O}_{3}$ \\
\hline Variolink Esthetic DC & Ivoclar Vivadent & $\begin{array}{l}\text { Monomer matrix: UDMA and further methacrylate monomers } \\
\text { Inorganic fillers: ytterbium trifluoride and spheroid mixed oxide } \\
\text { Particle size: } 0.04-0.2 \mu \mathrm{m} \\
\text { Inorganic fillers: } \sim 38 \text { vol. } \%\end{array}$ \\
\hline Adhes Universal & Ivoclar Vivadent & $\begin{array}{l}\text { 2-hydroxyethyl methacrylate BisGMA, ethanol, 1,10-decandiol } \\
\text { dimethacrylate, methacrylated phosphoric acid ester, } \\
\text { 2-dimethylaminoethyl methacrylate } \\
\text { Camphorquinone }\end{array}$ \\
\hline Monobond N & Ivoclar Vivadent & $\begin{array}{l}\text { Alcohol solution of methacrylate, phosphoric acid methacrylate, } \\
\text { and sulfide methacrylate }\end{array}$ \\
\hline Epoxy resin sheets & Carbotec & Glass silk fabric/epoxy resin \\
\hline
\end{tabular}


for 2 hours. The finishing of the disks was limited to the removal of the sprue using a fine diamond bur to prevent introduction of any variability in the thickness of the disks. For cementation of the dentin analogues, disks measuring $10 \mathrm{~mm}$ in diameter and $2.5 \mathrm{~mm}$ in thickness were shaped from epoxy resin sheets (Carbotec) using silicon carbide (180 grit) abrasive papers. In preparation for their cementation to the resin disk analogues, IPS e.max CAD and VITA Suprinity disks $(n=10)$ were etched with $5 \%$ hydrofluoric acid (IPS Ceramic Etching Gel; Ivoclar Vivadent) for $20 \mathrm{~s}$ and then thoroughly rinsed. Finally, the specimens were primed with Monobond $\mathrm{N}$ (Ivoclar Vivadent) for $60 \mathrm{~s}$ and then air-dried. The DD cube $\mathrm{X}^{2}$ disks $(\mathrm{n}=10)$ were sandblasted using aluminium oxide $(50 \mu \mathrm{m})$ at 1 to 2 bar, primed with Monobond $\mathrm{N}$ for $60 \mathrm{~s}$, and then air-dried. The VITA Enamic disks $(n=10)$ were etched with $5 \%$ hydrofluoric acid for $60 \mathrm{~s}$, primed with Monobond $\mathrm{N}$ for $60 \mathrm{~s}$, and then air-dried. The epoxy resin disks were etched with $10 \%$ hydrofluoric acid for $30 \mathrm{~s}$ and then ultrasonically rinsed with distilled water for $5 \mathrm{~min}$. After etching, a thin layer of Adhese Universal (Ivoclar Vivadent) was scrubbed on for $20 \mathrm{~s}$, followed by air-drying until a glossy immobile layer was achieved. For cementation, the dual-cured resin cement Variolink Esthetic DC (Ivoclar Vivadent) was used according to the manufacturer's instructions and placed in the centre of the disks. Finger pressure was used in cementing the disks; once the disks were joined together, the excess cement was removed using microbrushes. The threelayer assembly was light-cured using Bluephase G4 (Ivoclar Vivadent), and curing was performed through the CAD/CAM disks for $40 \mathrm{~s}$ while maintaining direct contact with the light-curing tip. The thickness of the cemented specimens was standardised at $4.5 \mathrm{~mm}$.

\section{Biaxial flexural strength testing}

Before testing, the cemented specimens were thermocycled for 10,000 cycles with a dwell time of $10 \mathrm{~s}$ (hot/cold each) and a transfer time of $5 \mathrm{~s}$. The cemented and uncemented ceramic disks were subjected to the B3B test using a universal testing machine (GB 5965; Instron) with a cell load of $5 \mathrm{kN}$ and a crosshead speed of $0.5 \mathrm{~mm} \cdot \mathrm{min}^{-1}$. The disks were laid on top of a stainless steel 3-ball assembly (each layer measuring $4 \mathrm{~mm}$ in diameter) and placed $120^{\circ}$ apart. The stainless-steel balls were then fixed on a circle measuring $10 \mathrm{~mm}$ in diameter. A 4-mm ball was used to centrally load the disks until fracture. The fracture load was recorded in newtons. The biaxial flexural strength was calculated using the following formula:

$$
S=-0.2387 P(X-Y) / d^{2},
$$

where $S$ is the flexural strength in megapascals, $P$ is the fracture load in newtons, and $d$ is the disk thickness at the site of fracture in millimetres. $X$ and $Y$ were calculated using the following formulas:

$$
\begin{aligned}
& X=(1+v) \ln \left(r_{2} / r_{3}\right)^{2}+([1-v] / 2)\left(r_{2} / r_{3}\right)^{2} \\
& \text { and } \quad Y=(1+v)\left(1+\ln \left[r_{1} / r_{3}\right]^{2}\right)+(1-v)\left(r_{1} / r_{3}\right)^{2},
\end{aligned}
$$

where $v$ is Poisson's ratio set to $0.25, r_{1}$ is the radius of the supportive circle $(8 \mathrm{~mm}), r_{2}$ is the radius of the loaded area $(2 \mathrm{~mm})$, and $r_{3}$ is the radius of the specimen (10 mm).

\section{Fractographic analysis}

The fractured specimens from each material were first examined; the pieces were reassembled, and photographs were then taken. A further detailed investigation $(n=3)$ was carried out using a scanning electron microscope (JSM-6360 LV; JEOL) for critical flaw assessment and analysis. Representative fractured specimens were thinly sputter-coated with a gold alloy before the SEM examination starting at $\times 30$ magnification and ending at $\times 140$ magnification.

\section{Statistical analysis}

The data were analysed using SPSS 26.0 (IBM). Descriptive statistics (median and interquartile range) were used to describe the biaxial flexural strength values in MPa. As the biaxial flexural strength values were skewed, the non-parametric Mann-Whitney $U$ and Kruskal-Wallis tests were used to compare the mean biaxial flexural strength values between the bonded and unbonded groups and among the four CAD/CAM materials, respectively. A $P$-value $<.05$ was considered statistically significant.

\section{RESULTS}

\section{Biaxial flexural strength}

The Unbonded group's mean ranks of biaxial flexural strength of the unbonded samples among the four $\mathrm{CAD} / \mathrm{CAM}$ materials tested are shown in Table 2. The difference in the biaxial flexural strength among the four materials was found to be significant $(P<0.0001)$, with DD cube $\mathrm{X}^{2}$ (566.3 MPa) demonstrating statistically significantly high biaxial flexural strength, followed by IPS e.max CAD (410.5 MPa), VITA Suprinity (330.7 MPa), and VITA Enamic (247.3 MPa).

The Bonded group's mean ranks of biaxial flexural strength of the bonded samples among the four CAD/ CAMmaterials are shown in Table 3. The difference among DD cubeX ${ }^{2}$ (676.5 MPa), VITA Enamic (619.3 MPa), IPS e.max CAD (605 MPa), and VITA Suprinity (544.2 MPa) was found to be statistically significant, with the former two materials demonstrating significantly higher mean ranks of B3B flexural strength compared with the latter two $(P=0.009)$. Among the four materials, DD cube $\mathrm{X}^{2}$ exhibited the highest biaxial flexural strength values, whereas VITA Suprinity exhibited the lowest. 
Table 2. Comparison of the mean ranks of the biaxial flexural strength (in MPa) of the unbonded samples among the four CAD/CAM materials tested.

\begin{tabular}{lccr}
\hline Material & Median (IQR) & Mean rank & $P$-value \\
\hline DD cubeX ${ }^{2}$ (Dental Direkt) & $566.3(145.5)^{\mathrm{a}}$ & 34.90 & $<0.0001$ \\
IPS e.max CAD (Ivoclar Vivadent) & $410.5(94.8)^{\mathrm{b}}$ & 25.00 & \\
VITA Suprinity (VITA Zahnfabrik) & $330.7(58.4)^{\mathrm{c}}$ & 16.40 & 5.70 \\
VITA Enamic (VITA Zahnfabrik) & $247.3(47.7)^{\mathrm{d}}$ &
\end{tabular}

Note: Different superscript letters indicate significant differences for each material (Tukey's honestly significant difference test). IQR, interquartile range.

Table 3. Comparison of the mean ranks of the biaxial flexural strength (in MPa) of the bonded samples among the four CAD/CAM materials tested.

\begin{tabular}{lccc}
\hline Material & Median (IQR) & Mean rank & $P$-value \\
\hline DD cubeX ${ }^{2}$ (Dental Direkt) & $676.5(126.9)^{\mathrm{a}}$ & 29.70 & 0.009 \\
IPS e.max CAD (Ivoclar Vivadent) & $605(104.3)^{\mathrm{b}}$ & 18.00 & 12.40 \\
VITA Suprinity (VITA Zahnfabrik) & $544.2(105.8)^{\mathrm{b}}$ & 21.90 & \\
VITA Enamic (VITA Zahnfabrik) & $619.3(35.7)^{\mathrm{a}}$ & \\
\hline
\end{tabular}

Note: Different superscript letters indicate significant differences for each material (Tukey's honestly significant difference test). IQR, interquartile range.

Table 4. Comparison of the mean ranks of the biaxial flexural strength (in MPa) between the bonded and unbonded samples in each of the four CAD/CAM materials tested.

\begin{tabular}{llccccc}
\hline \multirow{2}{*}{ Material } & \multicolumn{2}{c}{ Bonded } & & \multicolumn{2}{c}{ Unbonded } & \multirow{2}{*}{$P$-value } \\
\cline { 2 - 3 } & Median (IQR) & Mean rank & & Median (IQR) & Mean rank & \\
\hline DD cubeX2 (Dental Direkt) & $676.5(126.9)$ & 13.40 & & $566.3(145.5)$ & 7.60 & 0.028 \\
IPS e.max CAD (Ivoclar Vivadent) & $605.0(104.3)$ & 15.30 & & $410.5(94.8)$ & 5.70 & $<0.0001$ \\
VITA Suprinity (VITA Zahnfabrik) & $544.2(105.8)$ & 15.50 & & $330.7(58.4)$ & 5.50 & $<0.0001$ \\
VITA Enamic (VITA Zahnfabrik) & $619.3(35.7)$ & 15.50 & & $247.3(47.7)$ & 5.50 & $<0.0001$ \\
\hline
\end{tabular}

Note: IQR - interquartile range

The mean ranks of the biaxial flexural strength of the bonded and unbonded samples in each of the four CAD/CAM materials are shown in Table 4. The biaxial flexural strength values of the bonded samples were significantly higher than those of the unbonded samples among all four CAD/CAM materials.

\section{Fractographic analysis}

For DD cubeX ${ }^{2}$, a central void from which cracks radiated, leaving multiple pieces in varying sizes, caused by the shattering of the samples was recurrently observed (Figures 1a, b). The complete debonding of all the disks subjected to the B3B flexural stress was also noted. The SEM examination revealed multiple fracture planes and numerous features characteristic of fractured ceramic surfaces. The origins of the fractures were clearly discernible with visible hackles, compression curls, and crack arrest lines (Figure 2).

With regards to IPS e.max CAD, the unbonded and bonded disks showed similar fracture patterns splitting into three or four large fragments (Figures 1c, d). Four bonded samples exhibited some fragments still attached to the resin disks, whereas all the other samples were completely debonded after testing. The fracture surfaces appeared relatively smooth at higher magnification.
Fractographic fracture features were observed less frequently. Roughness, crack origins, compression curls, and Wallner lines were evident (Figure 3).

As for VITA Suprinity, the unbonded and bonded disks fractured into three or four fragments; however, some fragments were shattered into small pieces (Figures 1e, f). Six bonded samples had fragments that remained attached to the resin disks, whereas four were completely debonded after testing. The SEM observations showed many of the same features, such as fracture origins, arrest lines, hackles, Wallner lines, and compression curls. In addition, semi-elliptical depressions, where some fragments were apparently lost, were determined to be visible during the examination (Figure 4).

Finally, for VITA Enamic, the unbonded and bonded disks fractured into two or three large fragments (Figures 1g, h). Of the ten bonded samples tested, only one completely debonded, whereas all the other samples exhibited large fragments still attached to the underlying resin disks. Higher magnification revealed a rough corrugated surface resembling a composite resin fracture. Similar fracture features were present (e.g., fracture origins and compression curls). However, multiple crack planes, where fragments were lost, were evident. Some samples showed signs of delamination on the fractured surface (Figure 5). 
Unbonded Samples

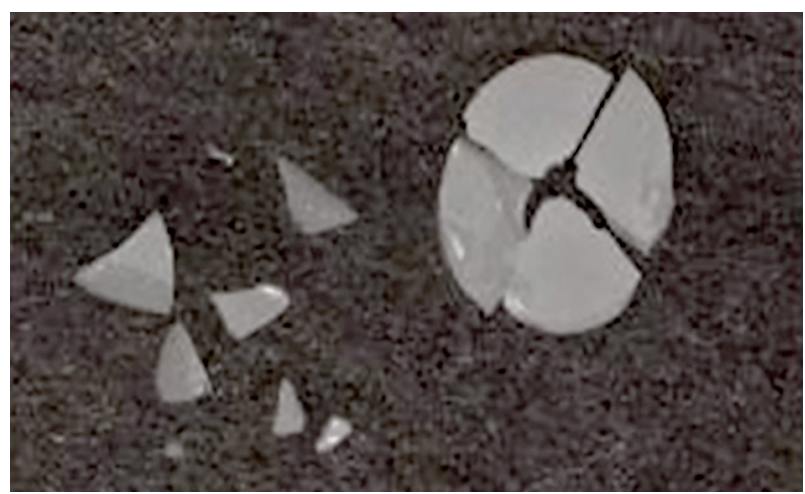

a) DD cube $X^{2}$

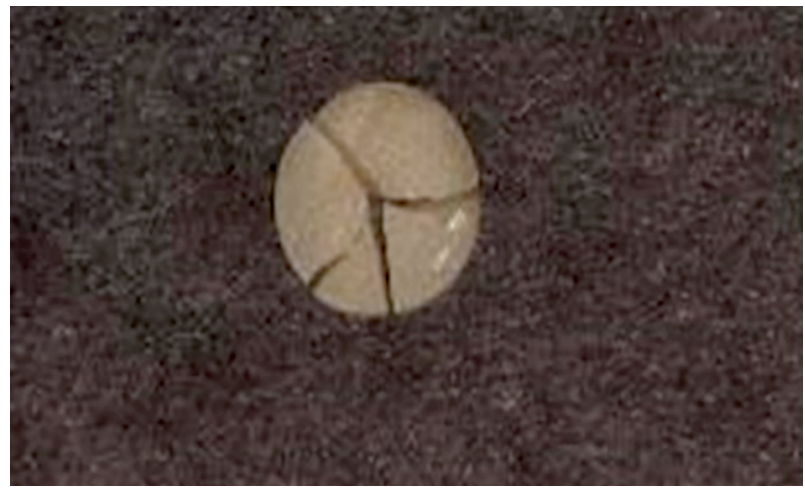

c) IPS emax CAD

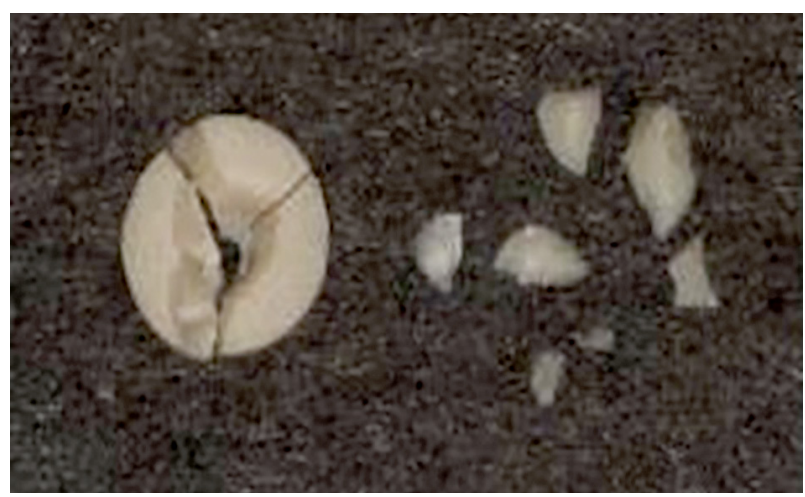

e) Vita Suprinity

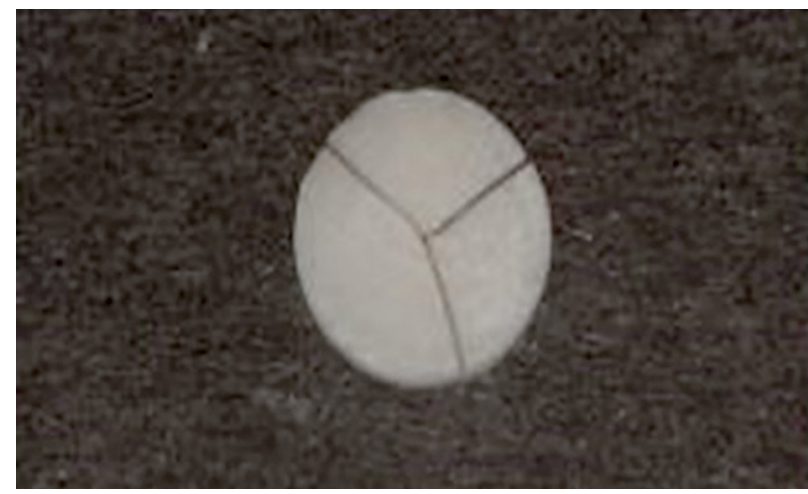

g) Vita Enamic
Bonded Samples

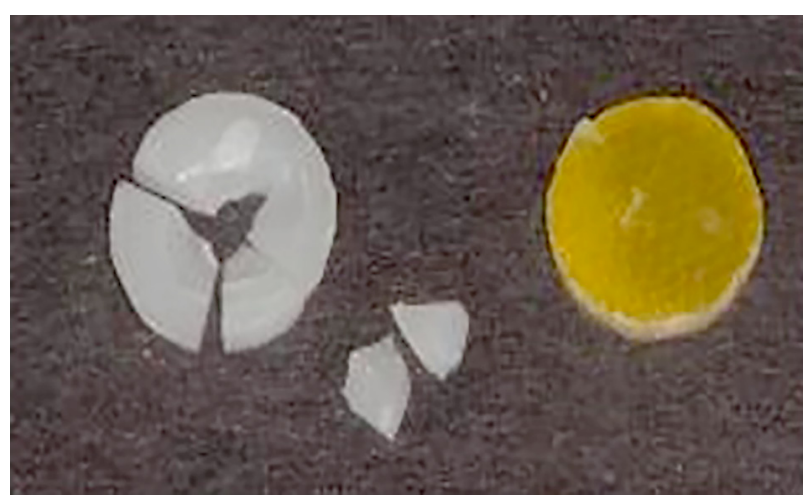

b) DD cube $X^{2}$

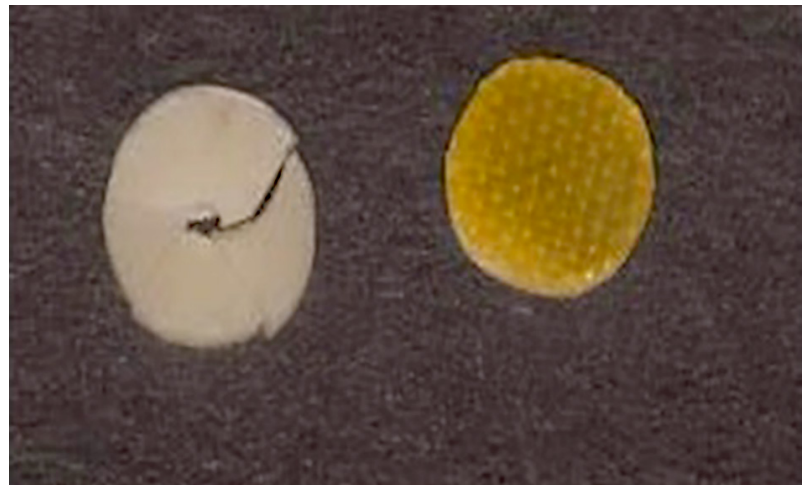

d) IPS emax CAD

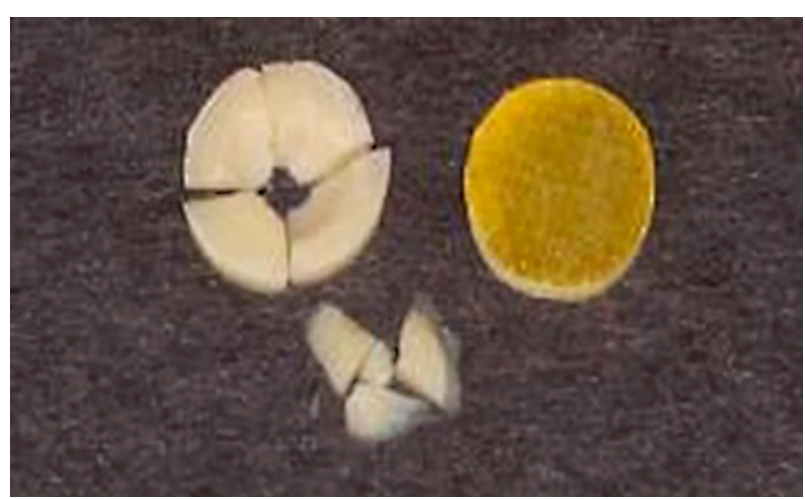

f) Vita Suprinity

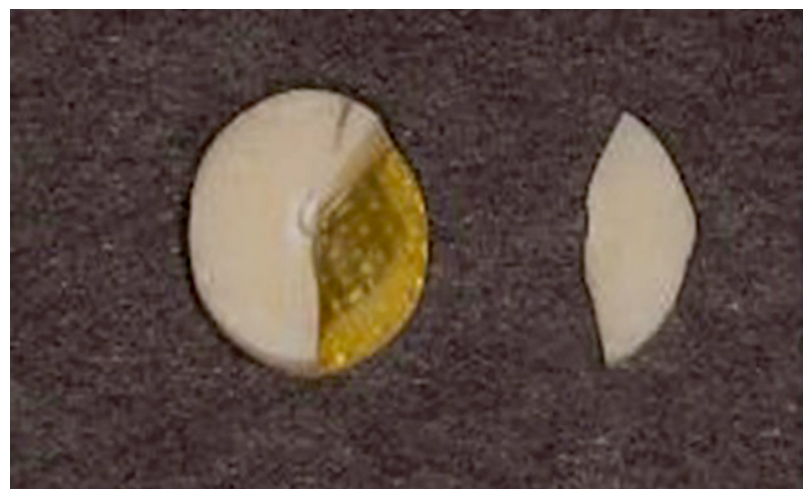

h) Vita Enamic

Figure 1. Reassembled representative samples of the fractured unbonded and bonded CAD/CAM disks. The centre of the disks marks the origin of the fracture. 


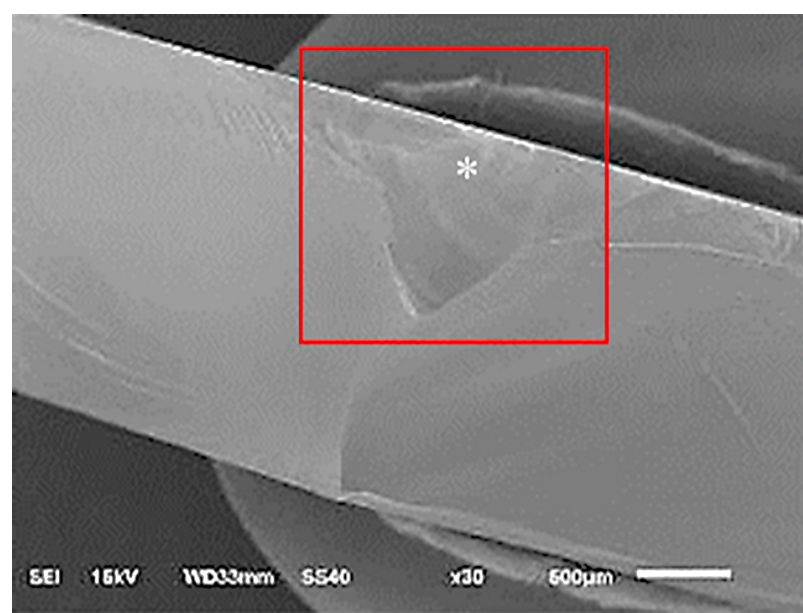

a)

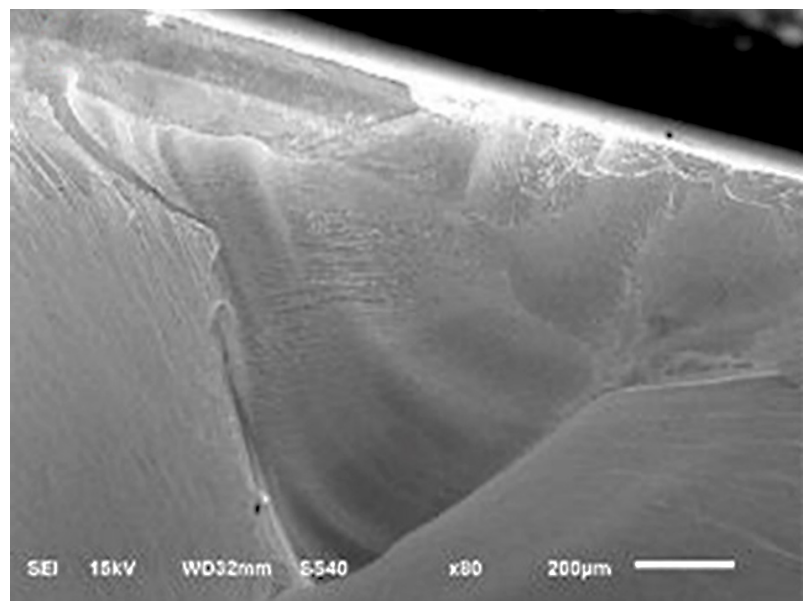

b)

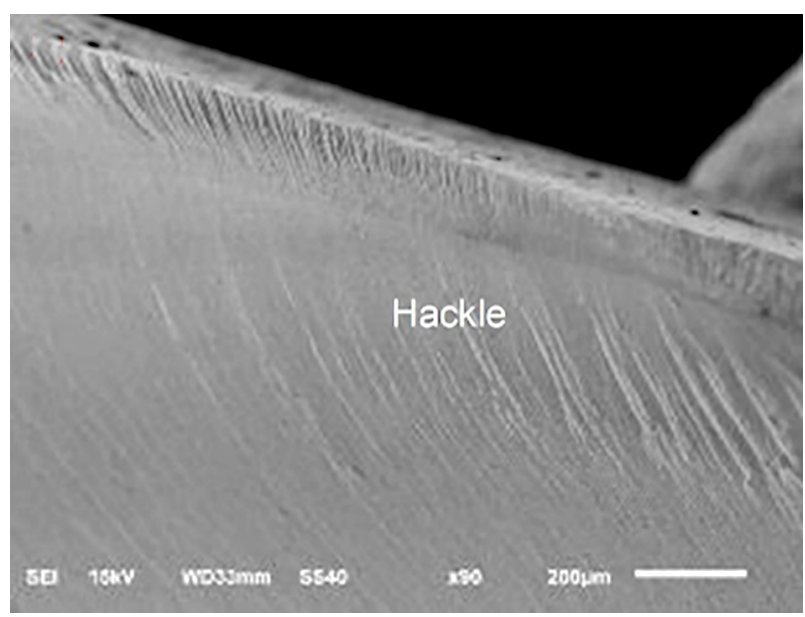

c)

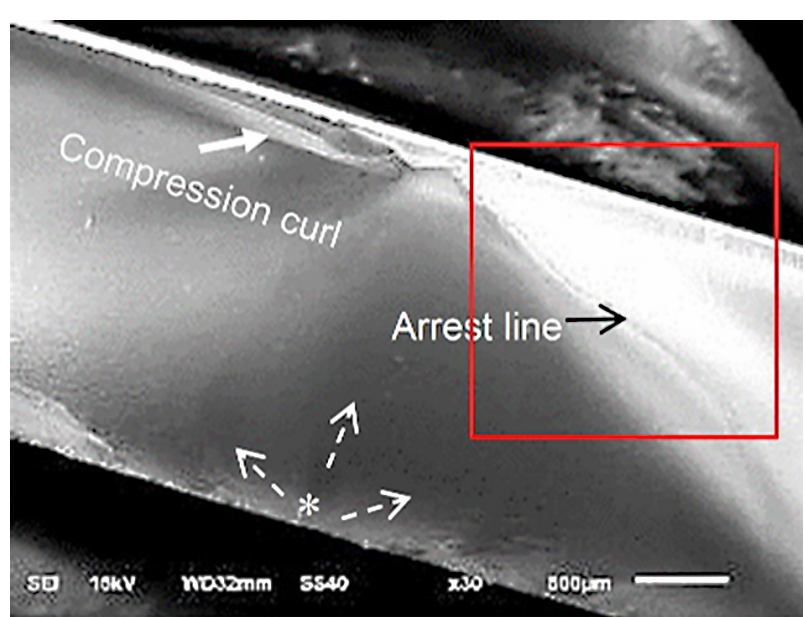

d)

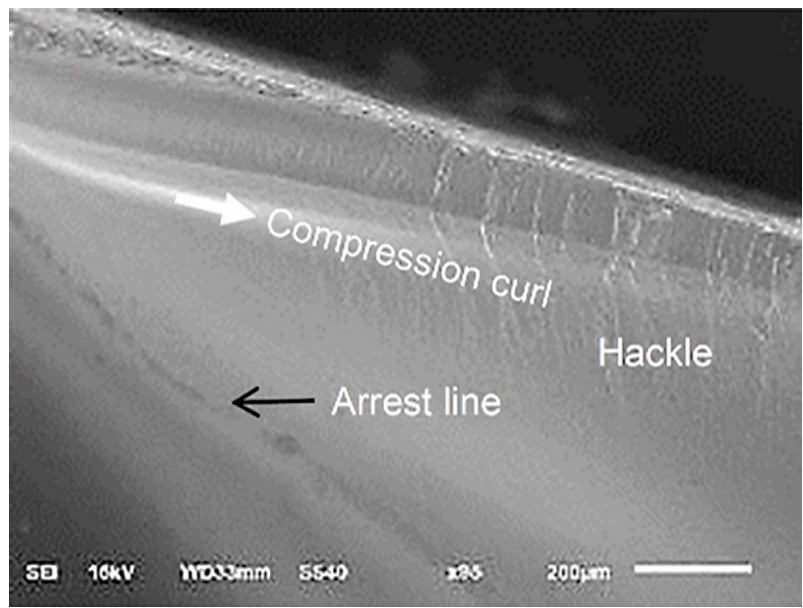

e)

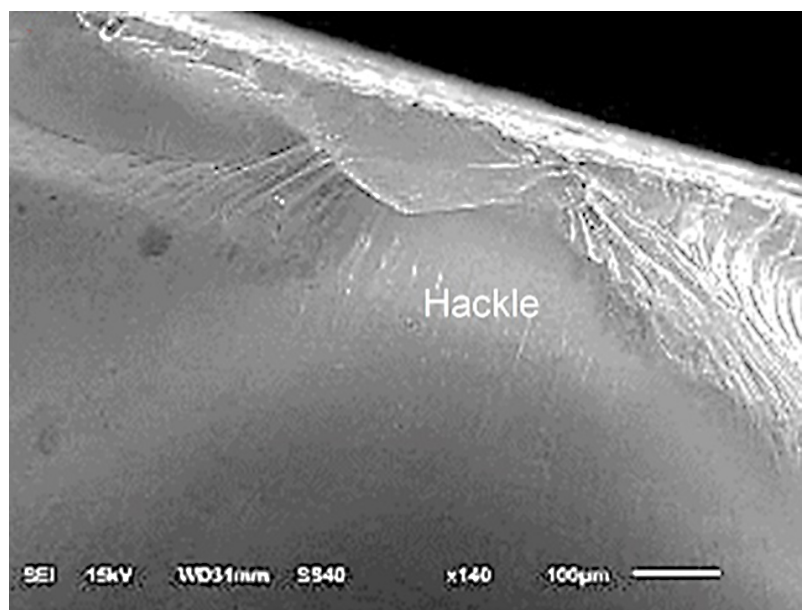

f)

Figure 2. Representative scanning electron microscopic (SEM) images of the unbonded $(\mathrm{a}-\mathrm{c})$ and bonded $(\mathrm{d}-\mathrm{f})$ ceramic DD cubeX2 (Dental Direkt, Spenge, Germany) disks. a) SEM image showing the origin of the crack (asterisk) that led to the fracture and detachment of the shattered fragments, resulting in a void from which another crack radiated to the bottom of the disk. b) SEM image at higher magnification showing multiple planes of fracture within the void. c) SEM image showing hackles, a common feature observed in ceramic fractures. d) SEM image showing the origin (asterisk) and direction of the crack propagation (broken white arrows) as well as a sharp arrest line (solid black arrow) indicative of a momentary arrest of the crack's propagation. e) SEM image at higher magnification showing a compression curl (solid white arrow) at the compression side as well as hackles. f) Closeup SEM image showing hackles as well as a small void from which small fragments were detached. 


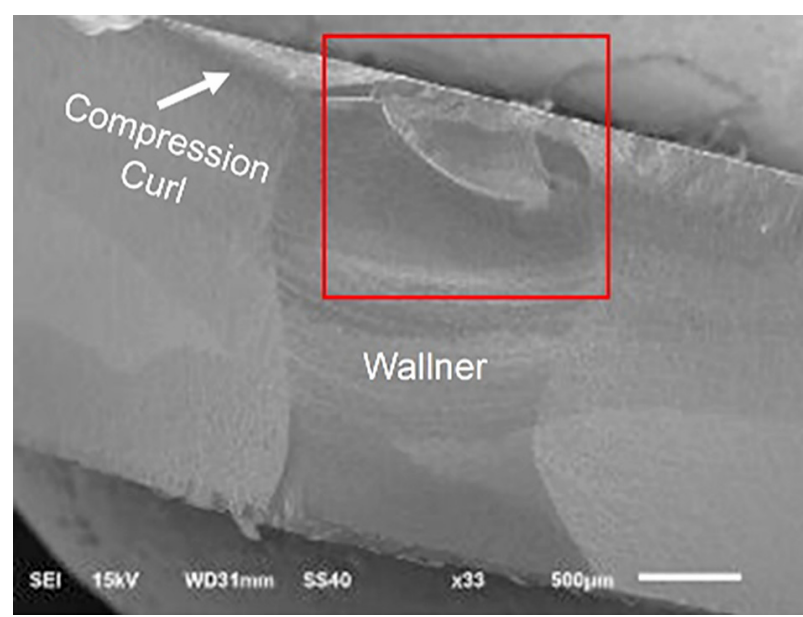

a)

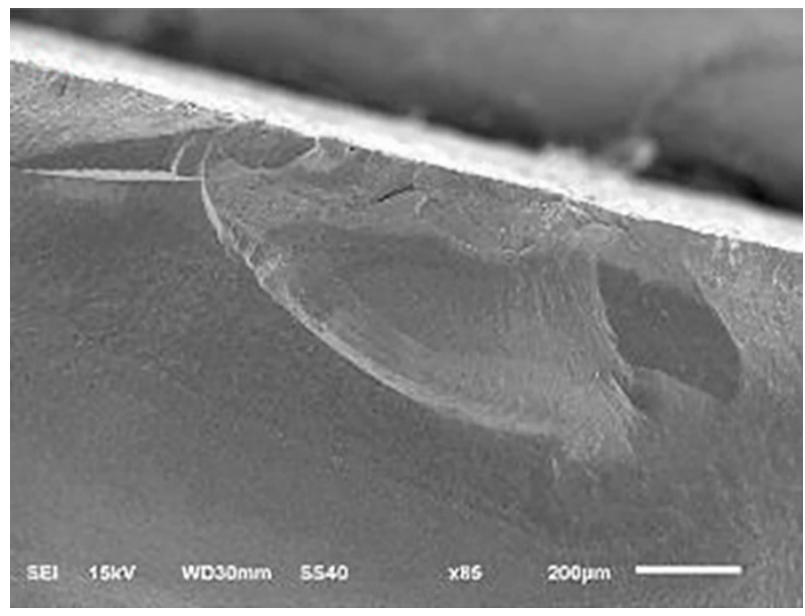

b)

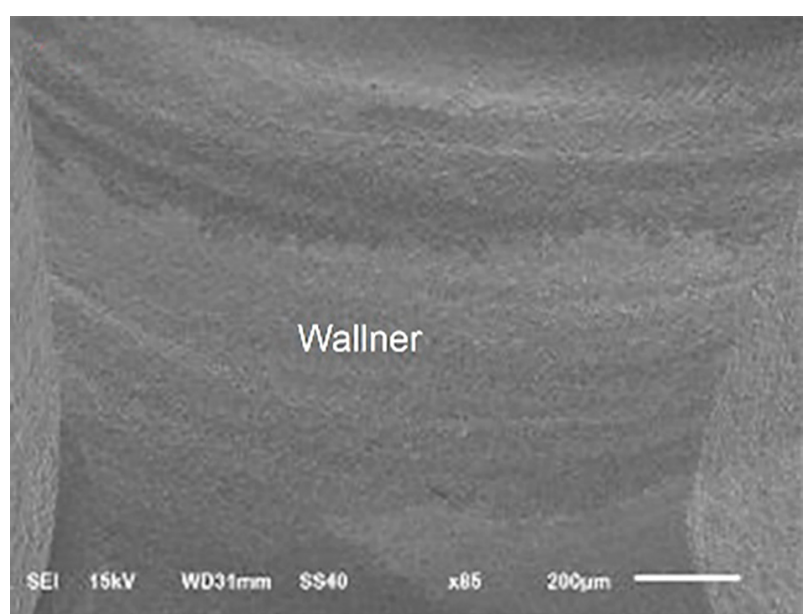

c)

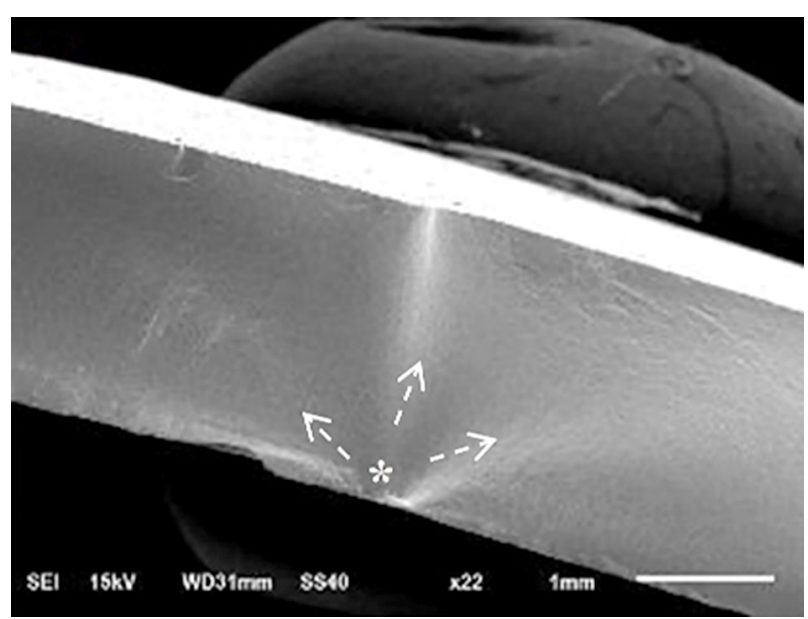

d)

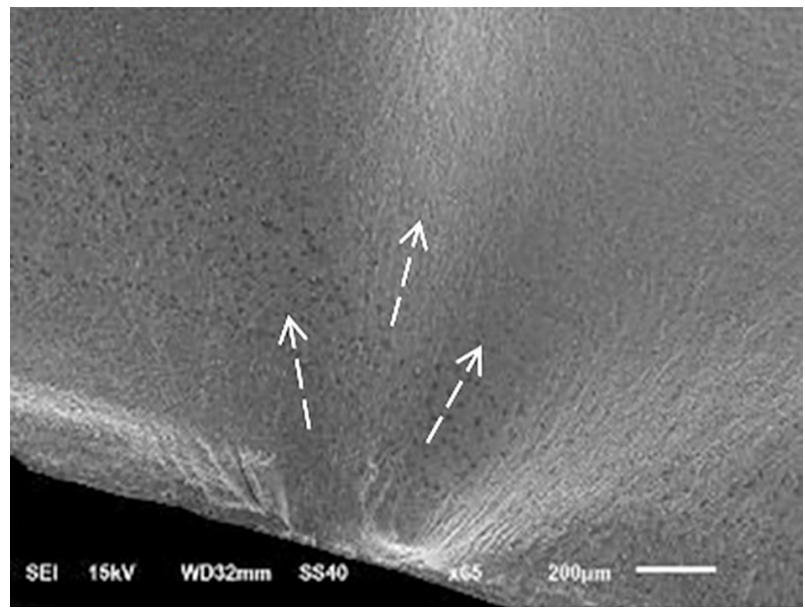

e)

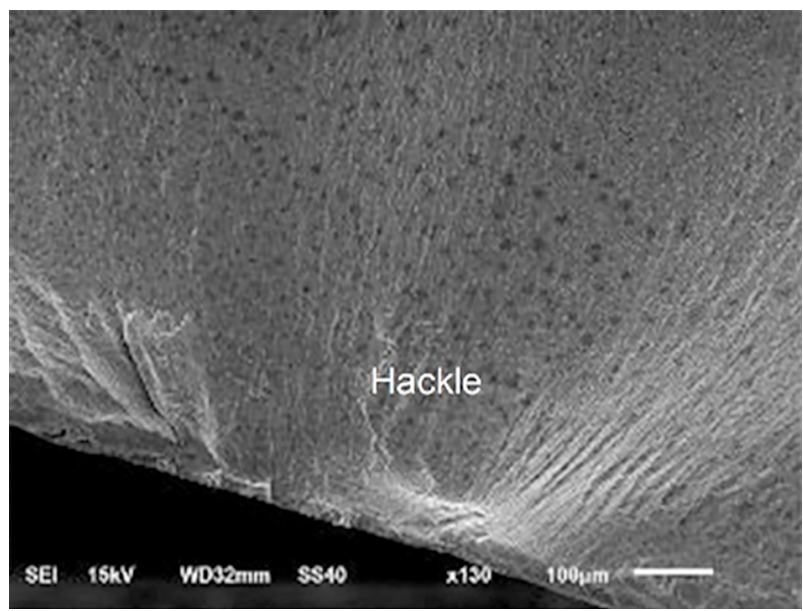

f)

Figure 3. Representative scanning electron microscopic (SEM) images of the unbonded $(\mathrm{a}-\mathrm{c})$ and bonded (d-f) ceramic IPS e.max CAD (Ivoclar Vivadent, Schaan, Lichtenstein) disks. a) SEM image showing compression curls (solid white arrow) and Wallner lines. These tracks were generated by the interaction between the propagating crack fronts and discontinuities within the sample. b) SEM image showing a void left behind by the forces applied by the loading ball. c) SEM image at higher magnification showing Wallner lines. (d, e) SEM images showing the origin (asterisk) and direction of the crack propagation of the fracture (broken white arrows). f) SEM image showing hackle lines indicative of the local direction of the crack as well as multiple voids. 


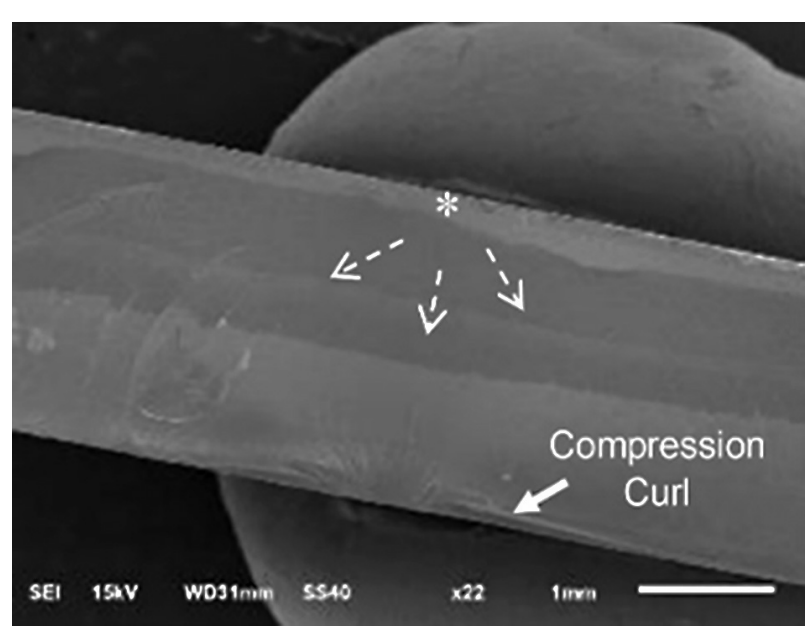

a)

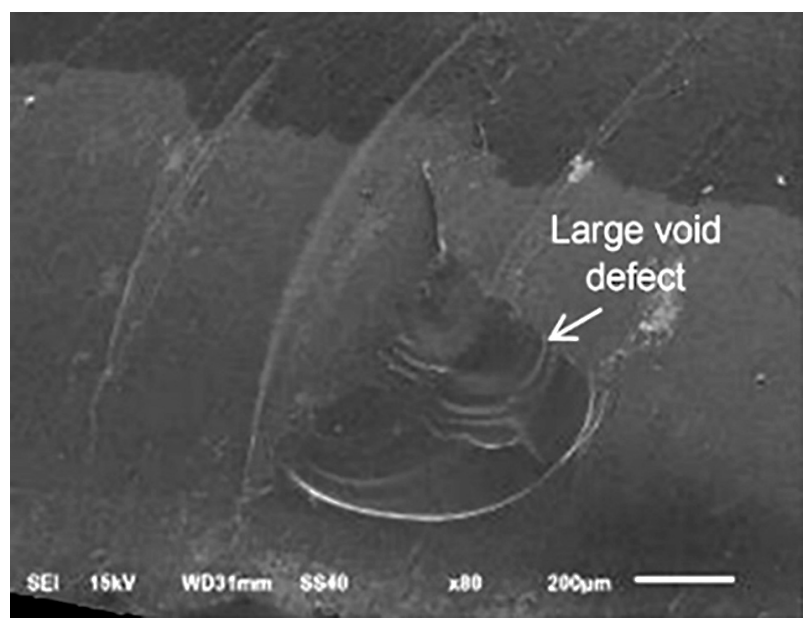

b)

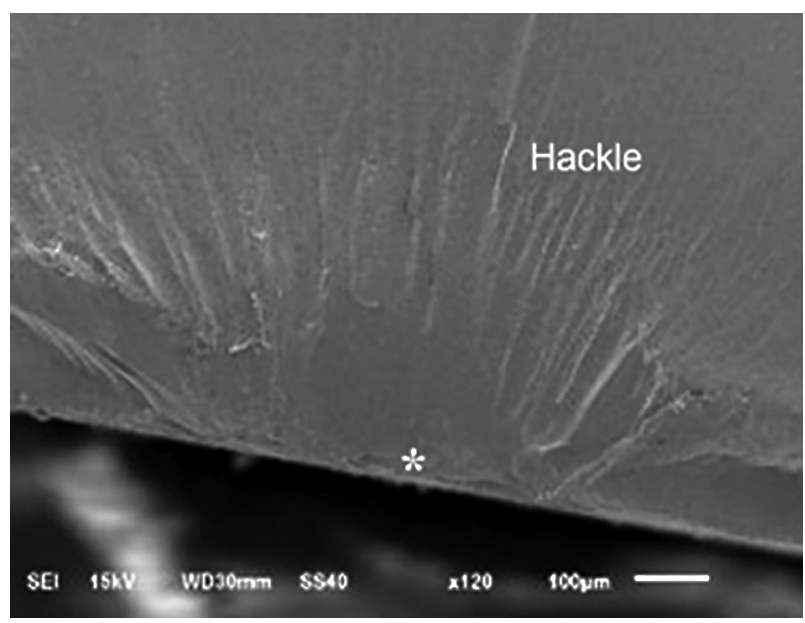

c)

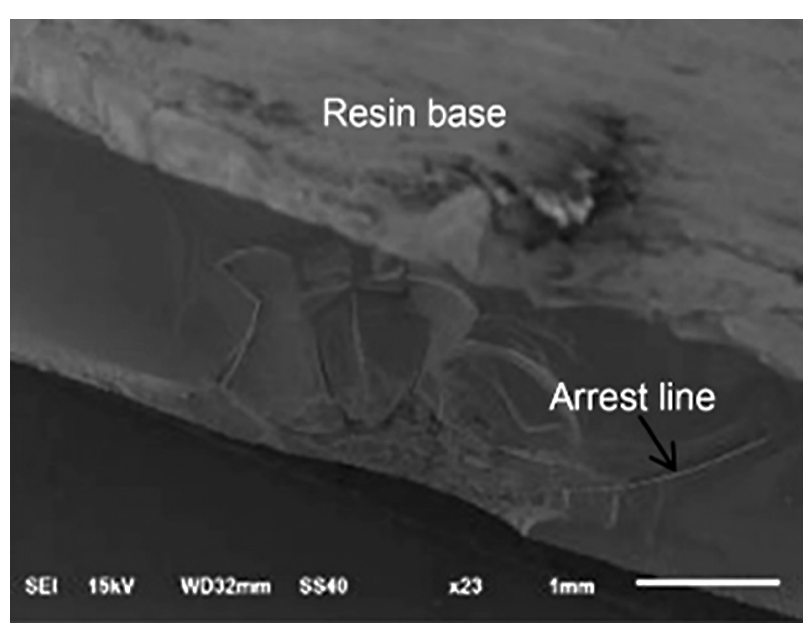

d)

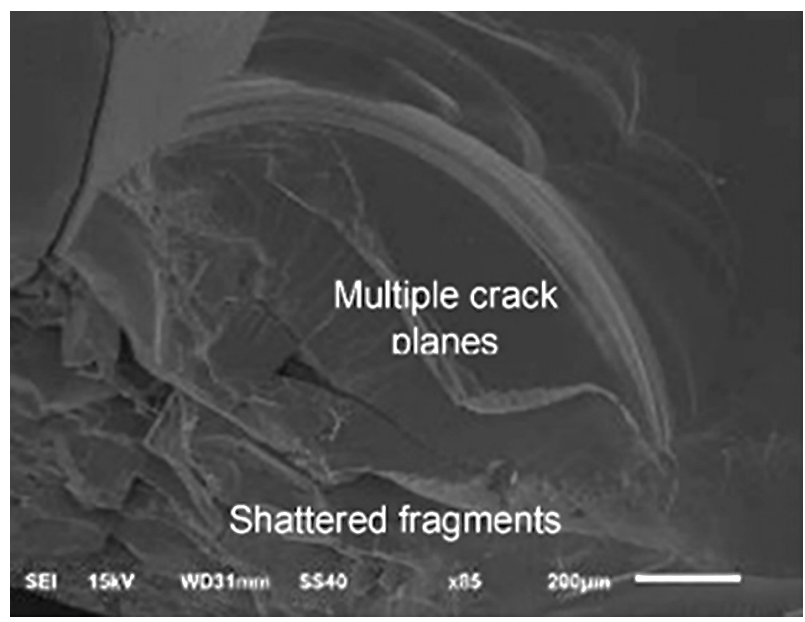

e)

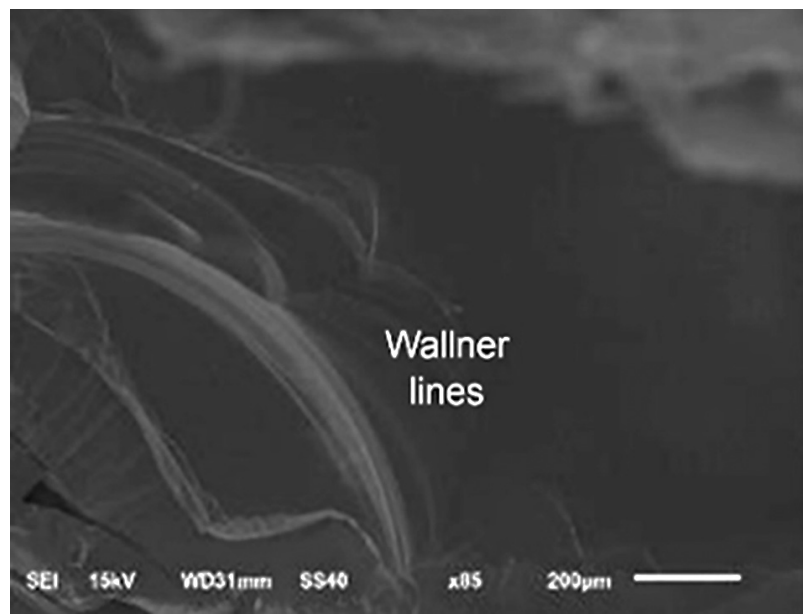

f)

Figure 4. Representative scanning electron microscopic (SEM) images of the unbonded (a-c) and bonded (d-f) ceramic VITA Suprinity (VITA Zahnfabrik, Bad Säckingen, Germany) disks. a) SEM image showing the origin (asterisk) and direction of the crack propagation (dotted white arrows) as well as a compression curl (solid white arrow). b) SEM image showing a large void (solid white arrow) defect within the disk, which may have been caused by processing issues. Mist lines were generated by the void. c) SEM image showing hackle lines in the area where the loading ball (piston) was applied and marking the origin of the crack (asterisk). d) SEM image showing several voids and fragmented pieces throughout the thickness of the disk. This may indicate multiple defects within the ceramic caused by processing issues. Interestingly, this sample displayed the lowest strength, fracturing at 1670 N. e,f) SEM images showing ceramic fracture features, including hackles and Wallner lines. 


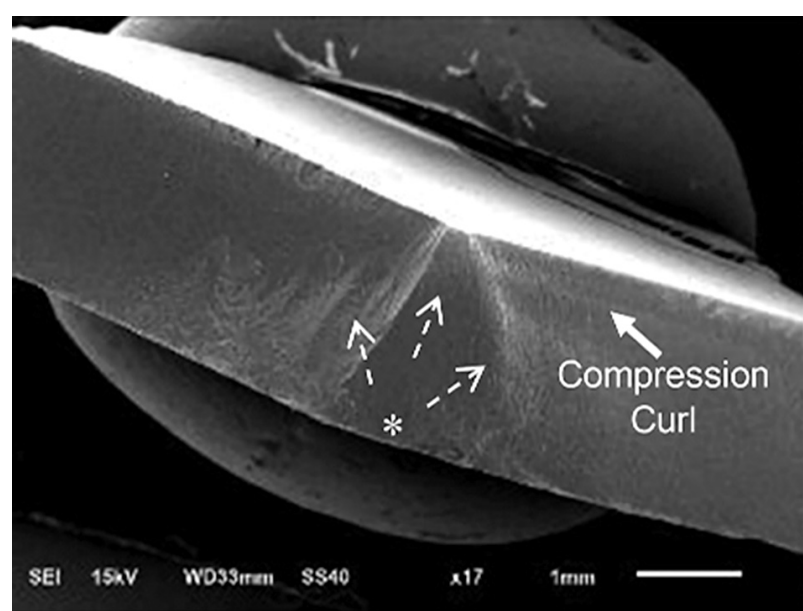

a)

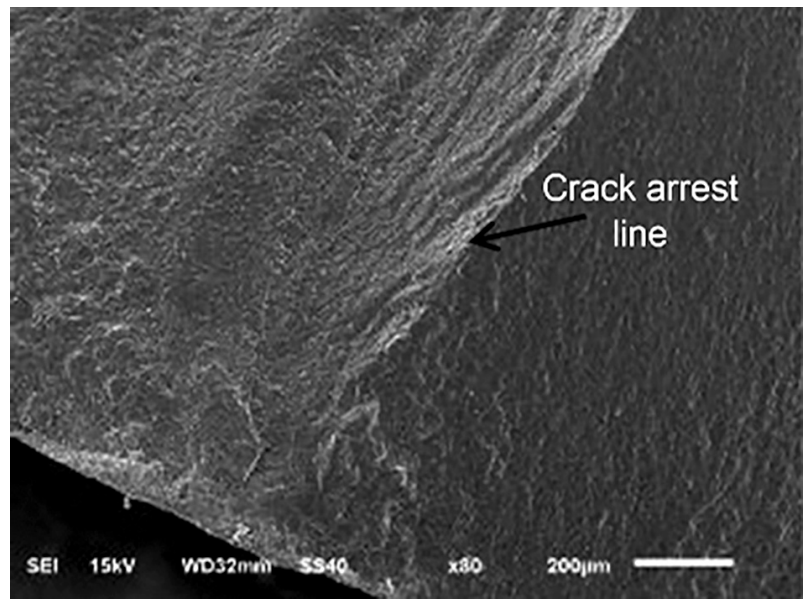

b)

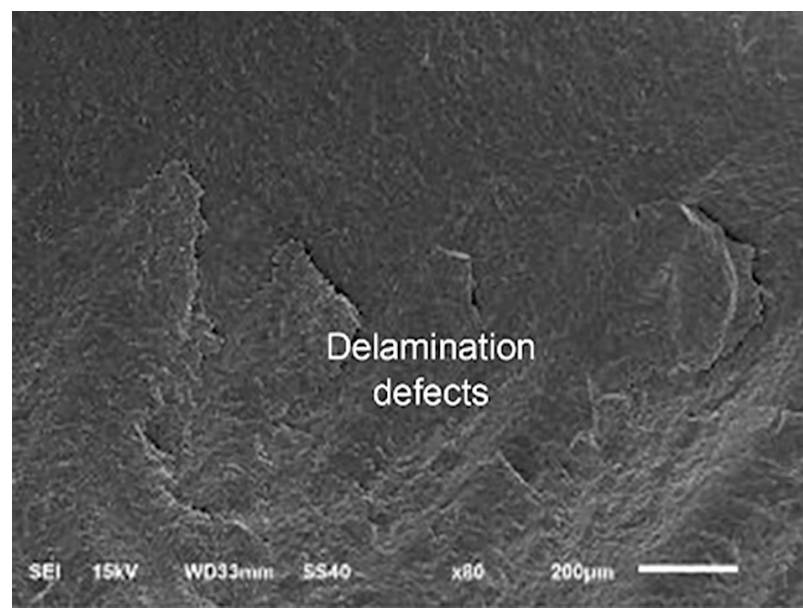

c)

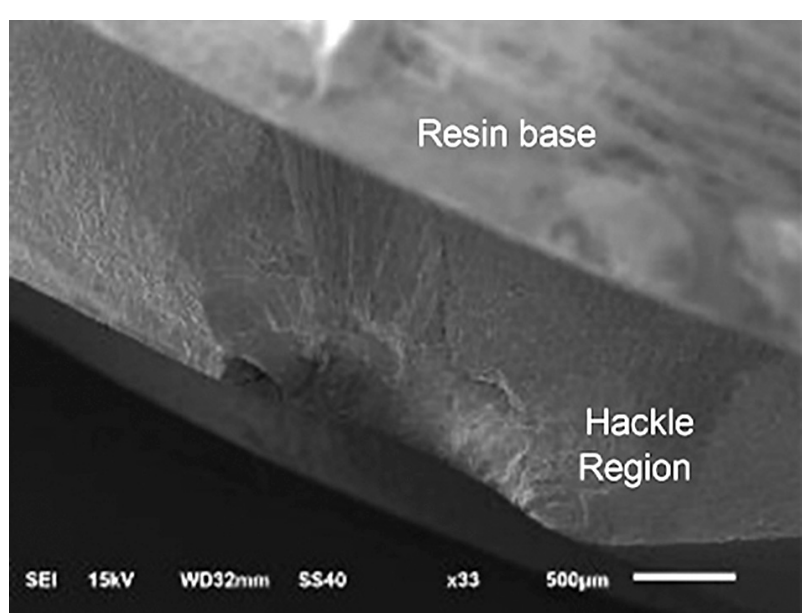

d)

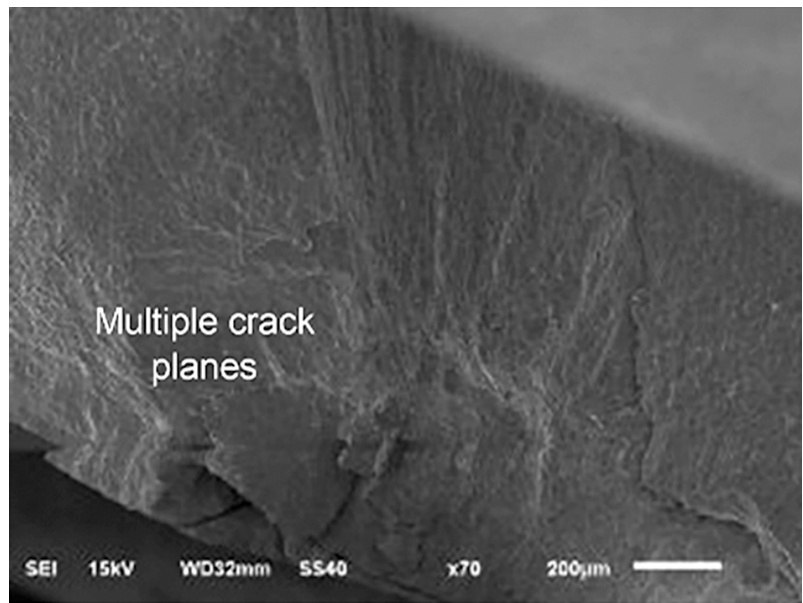

e)

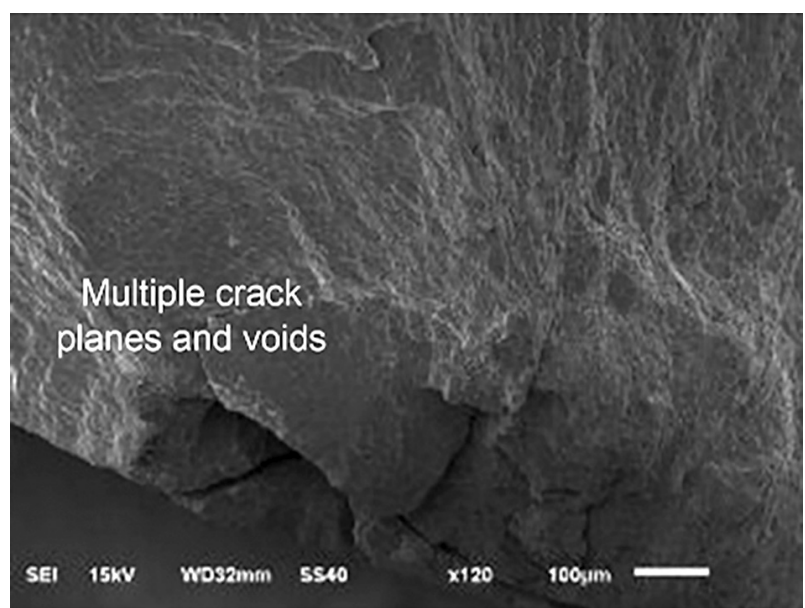

f)

Figure 5. Representative scanning electron microscopic (SEM) images of the unbonded $(\mathrm{a}-\mathrm{c})$ and bonded (d-f) polymer-infiltrated ceramic network VITA Enamic (VITA Zahnfabrik, Bad Säckingen, Germany) disks. Fracture features similar to those found in ceramic disks can be seen. The fast fracture of the disks resulted in rougher surfaces with such features as multiple crack planes, delamination defects, hackle lines, arrest line, and compression curls. 


\section{DISCUSSION}

This in vitro study measured and compared the B3B biaxial flexural strength values of four bonded and unbonded $\mathrm{CAD} / \mathrm{CAM}$ materials, followed by a fractographic analysis. A significant difference in the biaxial flexural strength between the unbonded specimens was found, with $\mathrm{DD}$ cube $\mathrm{X}^{2}$ displaying the highest strength, followed by IPS e.max CAD, VITA Suprinity, and VITA Enamic. Therefore, the first null hypothesis was rejected. Similar results were reported by previous studies where monolithic zirconia achieved the highest strength values and PICN displayed the lowest $[25,26]$. DD cube $\mathrm{X}^{2}$ exhibiting the highest values was an expected outcome: As described by the manufacturer, it is a monolithic zirconium consisting of a $5 \mathrm{~mol}$ \% yttria oxide, thus allowing for the stabilisation of $\sim 53 \%$ cubic and $47 \%$ tetragonal crystals. Based on the transformation toughening phenomenon, when subjected to mechanical forces, tetragonal crystals transform into a monoclinic phase, resulting in a local increase in the volume that, in turn, hinders the crack propagation and increases the strength of zirconium materials $[8,26]$. In this study, IPS e.max CAD exhibited higher flexural strength compared with VITA Suprinity. Nishioka et al. [26] obtained similar results, whereas Sen and Us reported opposite findings. IPS e.max CAD and VITA Suprinity are both lithium disilicate-based materials, although the latter material is infiltrated with zirconia crystals, a feature that should increase the strength of the material [9]. However, this claim could not be explicitly proven, with Ramos et al. having observed that zirconia infiltration did not improve the fracture toughness [30]. Furthermore, a study by Belli et al. did not detect zirconia crystals within the glassy matrix of VITA Suprinity [31].

With regard to the flexural strength between the bonded specimens, a significant difference was found among the $\mathrm{CAD} / \mathrm{CAM}$ materials, thereby rejecting the second null hypothesis. Interestingly, DD cube $\mathrm{X}^{2}$ and VITA Enamic exhibited the highest strength values, whereas IPS e.max CAD and VITA Suprinity had the lowest. Our results differ from those obtained by some studies where VITA Suprinity showed the highest strength values, followed by IPS e.max CAD and VITA Enamic; however, this can be attributed to the different sample preparation, ageing, and loading methods used $[4,6,24,29]$. VITA Enamic is characterised by a secondary polymerised monomer infiltrated with a pre-sintered glass-ceramic, resulting in a true skeleton structure that facilitates effective stress distribution in all directions. In addition, a distinctive feature of VITA Enamic is the honeycomb structure it exhibits once etched with hydrofluoric acid during the bonding procedure $[13,14]$. This feature allows for micromechanical bonding with the resin cement and is believed to be responsible for the material's higher bond strength [32]. These characteristics and the fact that the specimens were cemented on resin disks could explain the high biaxial flexural strength values of the bonded VITA Enamic.

The third null hypothesis was rejected because a significant difference in the biaxial flexural strength between the unbonded and bonded groups was determined. Adhesion to a substrate has been shown to affect the strength of restorative materials $[27,33,34]$. As explained by Wang et al., when cementing with a resin cement, a bridging effect occurs on the interfacial surface defects as a result of the volumetric shrinkage of the resin cement [34]. This shrinkage leads to the development of tensile stresses at the cement layer and compressive stresses at the restorative layer, consequently strengthening the material and increasing its fracture strength.

The B3B test can be used for the biaxial strength testing of brittle ceramics. Compared with other biaxial strength testing methods, where samples have to be machined with high accuracy to avoid warping while testing, the B3B test does not require such preparations, thus allowing for an easier and faster test execution [35]. Although the B3B test is one of the standard tests used for ceramic specimens, the stress applied in this test is not symmetrically distributed, which, in turn, complicates a fractographic examination, as cracks within the ceramic samples tend to align themselves to run in between the supporting balls. This phenomenon is especially evident when the samples shatter. In this study, the SEM examination of the unbonded and bonded specimens displayed typical fracture features. It also emphasised the brittle nature of ceramics compared with PICN CAD/CAM materials. Fractures in all the tested materials began at the centre of the disks subjected to tensile stress, with cracks originating from surface defects within the material. The monolithic zirconia DD cube $\mathrm{X}^{2}$ and VITA Suprinity exhibited small, shattered pieces along with large voids within the disks, which can be attributed to their microstructure as well as manufacturing processing flaws [36]. On the other hand, VITA Enamic topographical fracture features resembled surfaces observed in composite restorations $[37,38]$. A considerable variation in the bonding to the substrate was observed, with all the samples from the DD cube $\mathrm{X}^{2}$ group showing complete debonding from the substrate and only one specimen from the VITA Enamic group displaying complete debonding. This outcome may be attributed to the resin component of the VITA Enamic allowing chemical bonding with the cement and dentin analogue. This study has a few limitations. The materials were fabricated into simple disk-shaped specimens, a single type of resin cement was used, and one form of ageing was implemented. Subsequent studies using fatigue testing, different cementation, and ageing protocols, as well as specimens shaped into crowns or onlays would better represent the clinical situation. 


\section{CONCLUSIONS}

Within the limitations of this study, it can be concluded that the biaxial flexural strength of CAD/CAM materials depends on their microstructure. Furthermore, bonding increases the strength of these materials regardless of their type. Finally, bonded VITA Enamic showed biaxial flexural strength comparable with that of DD cubeX ${ }^{2}$. Therefore, VITA Enamic can be a viable option for the fabrication of indirect restorations for posterior teeth.

Aknowledgements

This work was supported in part by the Graduate Students Research Support Program, King Saud University. We would like to acknowledge Ivoclar Vivadent for providing the materials and light curing unit used in this study. The authors do not have any financial interest in the companies whose materials are included in this study.

\section{REFERENCES}

1. Kelly J.R., Benetti P. (2011): Ceramic materials in dentistry: Historical evolution and current practice. Australian Dental Journal, 56, 84-96. doi: 10.1111/j.1834-7819.2010.01299.x

2. Edelhoff D., Guth J.F., Erdelt K., Brix O., Liebermann A. (2019): Clinical performance of occlusal onlays made of lithium disilicate ceramic in patients with severe tooth wear up to 11 years. Dental Materials, 35, 1319-1330. doi: 10.1016/j.dental.2019.06.001

3. Pereira G.K.R., Guilardi L.F., Dapieve K.S., Kleverlaan C.J., Rippe M.P., Valandro L.F. (2018): Mechanical reliability, fatigue strength and survival analysis of new polycrystalline translucent zirconia ceramics for monolithic restorations. Journal of the Mechanical Behavior of Biomedical Materials, 85, 57-65. doi: 10.1016/j.jmbbm.2018.05.029

4. Furtado de Mendonca A., Shahmoradi M., Gouvea C.V.D., De Souza G.M., Ellakwa A. (2019): Microstructural and mechanical characterization of $\mathrm{CAD} / \mathrm{CAM}$ materials for monolithic dental restorations. Journal of Prosthodontics, 28, e587-e594. doi: 10.1111/jopr.12964

5. Spitznagel F.A., Boldt J., Gierthmuehlen P.C. (2018): $\mathrm{CAD} / \mathrm{CAM}$ ceramic restorative materials for natural teeth. Journal of Dental Research, 97, 1082-1091. doi: 10.1177/ 0022034518779759

6. Hamza T.A., Sherif R.M. (2017): Fracture resistance of monolithic glass-ceramics versus bilayered zirconia-based restorations. Journal of Prosthodontics, 28, e259-e264. doi: 10.1111/jopr.12684

7. Schultheis S., Strub J.R., Gerds T.A., Guess P.C. (2013): Monolithic and bi-layer CAD/CAM lithium-disilicate versus metal-ceramic fixed dental prostheses: Comparison of fracture loads and failure modes after fatigue. Clinical Oral Investigation, 17, 1407-1413. doi: 10.1007/s00784-0120830-1
8. Silva L.H.D., Lima E., Miranda R.B.P., Favero S.S., Lohbauer U., Cesar P.F. (2017): Dental ceramics: A review of new materials and processing methods. Brazilian Oral Research, 31, e58. doi: 10.1590/1807-3107BOR-2017. vol31.0058

9. Sen N., Us Y.O. (2018): Mechanical and optical properties of monolithic CAD-CAM restorative materials. Journal of Prosthetic Dentistry, 119, 593-599. doi: 10.1016/j.prosdent. 2017.06.012

10. IPS e.max CAD Monolithic Solutions Labside Instructions for Use. Ivoclar Vivadent. p. 1-68.

11. VITA SUPRINITY ${ }^{\circledR}$ PC Working Instructions. VITA Zahnfabrik p. 1-44.

12. DD Cube X2 The Zirconia Revolution. Dental Direkt. p. 1-6.

13. VITA ENAMIC $\AA$ for CEREC $® /$ inLab $\AA, 2012$ VITA Zahnfabrik Working Instructions.

14. Mainjot A.K., Dupont N.M., Oudkerk J.C., Dewael T.Y., Sadoun M.J. (2016): From artisanal to CAD-CAM blocks: State of the art of indirect composites. Journal of Dental Research, 95, 487-495. doi: 10.1177/0022034516634286

15. Stawarczyk B., Liebermann A., Eichberger M., Guth J.F. (2015): Evaluation of mechanical and optical behavior of current esthetic dental restorative $\mathrm{CAD} / \mathrm{CAM}$ composites. Journal of the Mechanical Behavior of Biomedical Materials, 55, 1-11. doi: 10.1016/j.jmbbm.2015.10.004

16. Awad D., Stawarczyk B., Liebermann A., Ilie N. (2015): Translucency of esthetic dental restorative CAD/CAM materials and composite resins with respect to thickness and surface roughness. Journal of Prosthetic Dentistry, 113, 534-540. doi: 10.1016/j.prosdent.2014.12.003

17. Gracis S., Thompson V.P., Ferencz J.L., Silva N.R., Bonfante E.A. (2015): A new classification system for all-ceramic and ceramic-like restorative materials. International Journal of Prosthodontics, 28, 227-235. doi: 10.11607/ijp.4244

18. Lawson N.C., Bansal R., Burgess J.O. (2016): Wear, strength, modulus and hardness of $\mathrm{CAD} / \mathrm{CAM}$ restorative materials. Dental Materials, 32, e275-e283. doi: 10.1016/j. dental.2016.08.222

19. Leung B.T., Tsoi J.K., Matinlinna J.P., Pow E.H. (2015): Comparison of mechanical properties of three machinable ceramics with an experimental fluorophlogopite glass ceramic. Journal of Prosthetic Dentistry, 114, 440-446. doi: 10. 1016/j.prosdent.2015.02.024

20. Huang C.W., Hsueh C.H. (2011): Piston-on-three-ball versus piston-on-ring in evaluating the biaxial strength of dental ceramics. Dental Materials, 27, e117-e123. doi: 10. 1016/j.dental.2011.02.011

21. Wendler M., Belli R., Petschelt A., Mevec D., Harrer W., Lube T., Danzer R., Lohbauer U. (2017): Chairside CAD/ CAM materials. Part 2: Flexural strength testing. Dental Materials, 33, 99-109. doi: 10.1016/j.dental.2016.10.008

22. Wang F., Yu T., Chen J. (2020): Biaxial flexural strength and translucent characteristics of dental lithium disilicate glass ceramics with different translucencies. Journal of Prosthodontic Research, 64, 71-77. doi: 10.1016/j.jpor. 2019.04.007

23. Choi B.J., Yoon S., Im Y.W., Lee J.H., Jung H.J., Lee H.H. (2019): Uniaxial/biaxial flexure strengths and elastic properties of resin-composite block materials for CAD/CAM. Dental Materials, 35, 389-401. doi: 10.1016/j.dental.2018. 11.032 
24. Andrade J.P., Stona D., Bittencourt H.R., Borges G.A., Burnett L.H.J, Spohr A.M. (2018): Effect of different computer-aided design/computer-aided manufacturing (CAD/ CAM) materials and thicknesses on the fracture resistance of occlusal veneers. Operative Dentistry, 43, 539-548. doi: 10.2341/17-131-L

25. Kulkarni A., Rothrock J., Thompson J. (2020): Impact of gastric acid induced surface changes on mechanical behavior and optical characteristics of dental ceramics. Journal of Prosthodontics, 29, 207-218. doi: 10.1111/jopr.12716

26. Nishioka G., Prochnow C., Firmino A., Amaral M., Bottino M.A., Valandro L.F., Melo R.M. (2018): Fatigue strength of several dental ceramics indicated for CAD-CAM monolithic restorations. Brazilian Oral Research, 32, e53. doi: 10.1590/1807-3107bor-2018.vol32.0053

27. Longhini D., Rocha C., de Oliveira L.T., Olenscki N.G., Bonfante E.A., Adabo G.L. (2019): Mechanical Behavior of ceramic monolithic systems with different thicknesses. Operative Dentistry, 44, E244- E253. doi: 10.2341/18-083-L

28. Yan J., Kaizer M.R., Zhang Y. (2018): Load-bearing capacity of lithium disilicate and ultra-translucent zirconias. Journal of the Mechanical Behavior of Biomedical Materials, 88 , 170-175. doi: 10.1016/j.jmbbm.2018.08.023

29. Weitzel I., Rangel J.H.R., Perim M.P., Melo R.M., Borges A.L.S., Silva-Concilio L.R., Amaral M. (2020): Mechanical performance of monolithic materials cemented to a dentinlike substrate. Journal of Prosthetic Dentistry, 123, 753.e1753.e7. doi: 10.1016/j.prosdent.2019.12.021

30. Ramos N.C., Campos T.M., Paz I.S., Machado J.P., Bottino M.A., Cesar P.F., Melo R.M. (2016): Microstructure characterization and SCG of newly engineered dental ceramics. Dental Materials, 32, 870-878. doi: 10.1016/j.dental.2016. 03.018
31. Belli R., Wendler M., Ligny D., Cicconi M.R., Petschelt A., Peterlik H., Lohbauer U. (2017): Chairside CAD/CAM materials. Part 1: Measurement of elastic constants and microstructural characterization. Dental Materials, 33, 84-98. doi: 10.1016/j.dental.2016.10.009

32. Elsaka S.E. (2014): Bond strength of novel CAD/CAM restorative materials to self-adhesive resin cement: The effect of surface treatments. Journal of Adhesive Dentistry, 16, 531-540. doi: 10.3290/j.jad.a33198

33. Chen C., Trindade F.Z., Jager N., Kleverlaan C.J., Feilzer A.J. (2014): The fracture resistance of a CAD/CAM Resin Nano Ceramic (RNC) and a CAD ceramic at different thicknesses. Dental Materials, 30, 954-962. doi: 10.1016/j. dental.2014.05.018

34. Wang Y., Katsube N., Seghi R.R., Rokhlin S.I. (2007): Statistical failure analysis of adhesive resin cement bonded dental ceramics. Engineering Fracture Mechanics, 74, 1838-1856. doi: 10.1016/j.engfracmech.2006.11.006

35. Borger A., Supancic P., Danzer R. (2002): The ball on three balls test for strength testing of brittle discs: Stress distribution in the disc. Journal of European Ceramic Society, 22, 1425-1436. doi: 10.1016/S0955-2219(01)00458-7

36. Scherrer S.S., Lohbauer U., Della Bona A., Vichi A., Tholey M.J., Kelly J.R., van Nort R. Cesar P.F. (2017): ADM guidance-Ceramics: Guidance to the use of fractography in failure analysis of brittle materials. Dental Materials, 33, 599-620. doi: 10.1016/j.dental.2017.03.004

37. Quinn J.B., Quinn G.D. (2010): Material properties and fractography of an indirect dental resin composite. Dental Materials, 26, 589-599. doi: 10.1016/j.dental.2010.02.008

38. Thomaidis S., Kakaboura A., Mueller W.D., Zinelis S. (2013): Mechanical properties of contemporary composite resins and their interrelations. Dental Materials, 29, e132-e141. doi: 10.1016/j.dental.2013.04.025 